\title{
Uso de construções linguísticas abstratas na brincadeira entre pares de crianças
}

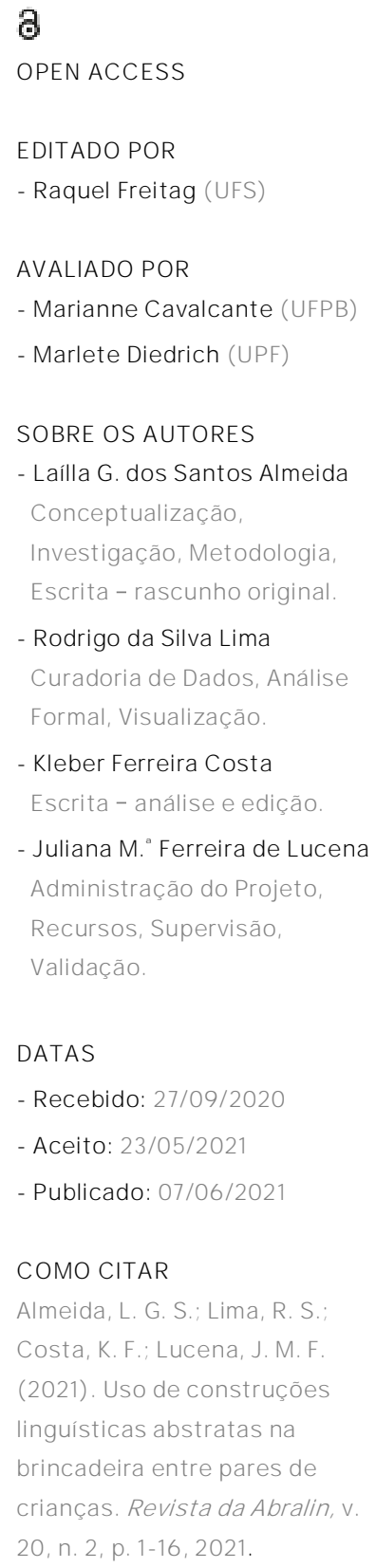

\author{
Laílla Geohana dos Santos ALM EIDA (D) \\ Universidade de Pernambuco (UPE) \\ Rodrigo da Silva LIMA (D) \\ Universidade de Pernambuco (UPE)) \\ Kleber Ferreira COSTA (D) \\ Universidade de Pernambuco (UPE) \\ J uliana M.․ Ferreira de LUCENA D \\ Universidade de Pernambuco (UPE)
}

\section{RESUMO}

O presente artigo tem o objetivo investigar como crianças de três anos, falantes de português brasileiro, engajam-se em processos de comunicação e de aquisição de linguagem, especificamente, de construções linguísticas abstratas, nas interações lúdicas com pares de idade. A perspectiva sociointeracionista e a abordagem baseada no uso para a aquisição da linguagem são colocadas em diálogo como base teórica para evidenciar como as crianças se comunicam por meio de recursos intersubjetivos e aprendem imitativamente construções linguísticas que ouvem no seu contexto sociocultural. Foram investigadas 10 crianças na faixa etária de três anos de idade que frequentavam uma creche Municipal Pública da Cidade do Recife. As crianças foram filmadas em situação de brincadeiras totalizando 12 sessões de videogravação, com 20 minutos de duração. Todas as sessões foram analisadas microgeneticamente. Foram identificados episódios interacionais que apresentaram as intenções comunicativas das crianças na brincadeira com os parceiros por meio de ações imitativas; e o emprego 


\section{REVISTA DA ABRALIN}

de construções linguísticas abstratas classificadas como afirmativas e interrogativas. Observou-se também o papel dos movimentos do corpo na comunicação intersubjetiva. Esta tinha o seu significado abreviado quando acompanhada do uso da construção linguística pelo interlocutor. Os dados apresentados permitem expandir os estudos na área, com o foco nas interações criança-criança falantes de português brasileiro, e podem oferecer referências empíricas que contribuam para o fortalecimento de pesquisas sobre a comunicação e a aquisição da linguagem como processos que se efetivam no uso mediante as necessidades interacionais.

\section{ABSTRACT}

This article aims to investigate how 3-year-old children, speakers of Brazilian Portuguese, engage in communication and language acquisition processes, specifically, abstract linguistic constructions, in playful interactions with peers. The socio-interactionist perspective and the use-based approach to language acquisition are placed in dialogue as a theoretical basis to show how children communicate through intersubjective resources and learn imitatively the linguistic constructions they hear in their sociocultural context. We investigated 10 children in the age group of 3-years-old who attended a public daycare in the city of Recife. The children were filmed in a play situation totaling 12 video sessions with 20 minutes. All sessions were analyzed microgenetically. Interactional episodes were identified that presented the children's communicative intentions in playing with partners through imitative actions; and the use of abstract linguistic constructions classified as affirmative and interrogative. The role of body movements in intersubjective communication was also observed. This had its abbreviated meaning when accompanied by the use of linguistic construction by the interlocutor. The data presented allows the expansion of studies in the area, with a focus on child-child interactions that speak Brazilian Portuguese, and can offer empirical references that contribute to the strengthening of research on communication and language acquisition as processes that are effective in the use through interactional needs.

PALAVRAS-CHAVE

Brincadeira. Interação social. Criança.

\section{KEYWORDS}

Play. Social interaction. Child. 


\section{REVISTA DA ABRALIN}

\section{Introdução}

O estudo da comunicação e da linguagem tem uma grande abrangência e dialoga com diferentes áreas do conhecimento. Embora esforços tenham sido feitos, especialmente entre linguistas e psicólogos, para compreender padrões universais e especificidades da comunicação e da linguagem humana (BAKHTIN, 1992; CAMERON-FAULKNER; MALIK; STEELE; CORETTA; SERRATRICE; LIEVEN, 2020; LISZKOWSKI; BROWN; CALLAGHAN; TAKADA; DE VOS, 2012; RISSMAN; GOLDIN-MEADOW, 2017; TOMASELLO, 2008), muito ainda precisa ser explorado para especificar o entendimento em relação a esses fenômenos. Um exemplo é refletir sobre o desenvolvimento das competências comunicativas e linguísticas das crianças em suas interações com os pares de idade em uma atividade que é intrinsecamente motivacional para elas, como o brincar.

Destaca-se que boa parte do que se sabe sobre a área ainda é fruto de pesquisas realizadas com díades adulto-criança falantes de língua inglesa. Um estudo que explora a qualidade da comunicação criança-criança falantes de português brasileiro pode ampliar e expandir o entendimento sobre a questão na direção do aprimoramento conceitual sobre o tema e de procedimentos metodológicos para melhor investigá-lo. Assim, colocam-se as seguintes questões neste artigo: (a) como crianças de três anos comunicam-se com seus pares de idades na brincadeira? Aos três anos, a criança já tem um repertório linguístico considerável e supõe-se que o colocará em uso nas interações com os parceiros junto com recursos dos quais dispõem, como os gestos, o olhar, o sorriso; (b) como as crianças de três anos se envolvem no processo de aquisição de linguagem nas brincadeiras com o parceiro? As situações de interações lúdicas são alçadas como contexto privilegiado de observação para as habilidades comunicacionais e linguísticas das crianças por ser uma atividade de alta motivação para elas.

Para dar suporte ao argumento defendido de um processo de comunicação e aquisição de linguagem nas interações sociais a partir de necessidades concretas das crianças, os estudos conduzidos por Michael Tomasello e colaboradores são colocados em discussão (BOHN; KACHEL; TOMASELLO, 2019; LIEVEN; BEHRENS; SPEARES; TOMASELLO, 2003; TOMASELLO, 2000). A abordagem baseada no uso para a compreensão da aquisição da linguagem argumenta que todas as crianças humanas estão biologicamente preparadas de várias maneiras para adquirir uma língua natural possuem aptidões cognitivas, sociocognitivas e fonoauditivas básicas para a ontogênese da linguagem (TOMASELLO, 2000). No entanto, cada criança tem que aprender as construções linguísticas particulares, concretas e abstratas, de sua língua nativa. Essa perspectiva caracteriza a linguagem das crianças não em termos de inato ou como uma gramática formal do adulto, mas tem como base os processos comunicacionais e cognitivos envolvidos (TOMASELLO, 2000; 2008).

Três conjuntos de processos são fundamentais para compreender como as crianças adquirem as construções linguísticas: (a) aprendizagem cultural por meio das ações imitativas; (b) discurso e conversação; e (c) abstração e esquematização (TOMASELLO, 2000). As crianças aprendem imitativamente expressões linguísticas concretas da linguagem que ouvem no seu contexto, e em seguida, usando suas habilidades cognitivas e sociocognitivas gerais (como, por exemplo, teoria da mente e 


\section{REVISTA DA ABRALIN}

compreensão de emoções), categorizam, esquematizam e combinam criativamente essas expressões às estruturas aprendidas individualmente. No processo de aquisição da linguagem, as crianças criam construções linguísticas abstratas, fazendo uso de artefatos simbólicos culturalmente convencionados em seus grupos sociais.

Entre crianças anglofalantes, as primeiras construções abstratas são do tipo: imperativas (Roll it! Smile! Push me!); transitivas simples (Ernie kissed her; Her kicked the ball); intransitivas simples (She's smiling; It's rolling); locativas (I put it on the table clean); resultativas (He wiped the table clean; She knocked him silly); passivas (I got hurt; He got kicked by the elephant); atributivas e identificativas (It's pretty; She's my mommy; It's a tape recorder) (TOMASELLO, 2003). Essas construções dependem de uma primeira etapa de aprendizagem imitativa (aprendizagem cultural), com alguma compreensão de papéis na interação, seguida de um processo de criação de analogias e mapeamento de estruturas para construção de ilha de verbos em torno de palavras específicas, que as crianças vão usar e expandir a sua competência linguística (TOMASELLO, 2000).

A interação social é uma condição básica para a criança demonstrar suas capacidades de produzir enunciados e atribuir significados às suas ações e às dos outros, expressando-as comunicativamente nas suas ações (BRUNER, 1997[1990]). Essa capacidade de produzir enunciado se justifica neste estudo também pela perspectiva bakhtiniana para quem a enunciação é o produto da interação de dois indivíduos socialmente organizados (BAKHTIN, 1992) ${ }^{1}$.

A linguagem humana é permeada de significados que constituem o conhecimento de uma sociedade. Esses significados permitem a compreensão do que está sendo transmitido ou expressado mediante a interação com o outro (BAKHTIN, 1992; BRUNER, 1983, 1997[1990]; TOMASELLO, 2003; VYGOTSKY, 1984; 1993). A linguagem apresenta um papel fundamental na construção da identidade do sujeito, pois não só tem a função de transmitir informações, como também cria realidades oferecendo novas concepções sobre o mundo. É, também, por meio da linguagem que o ser humano passa a referir e a significar suas ações, construindo seu conhecimento a partir das trocas interativas.

No desenvolvimento dos seres humanos, os processos de significação do mundo estão presentes muito cedo, já que o ambiente característico da espécie é o meio de interação social (VYGOTSKY, 1984). Neste meio, o locutor serve-se da língua para suas necessidades enunciativas concretas (BAKHTIN, 1992). Nas interações sociais, os sujeitos atribuem significados aos próprios comportamentos e aos comportamentos do outro, manifestando antes mesmo da aquisição da linguagem verbal, suas habilidades comunicativas, como movimentos, gestos e expressões emocionais (BRUNER, 1983).

Os processos de significação fazem parte das características humanas (BRUNER, 1997[1990]). Por meio desse sistema, o ser humano compreende as formas de compartilhamento dos elementos

\footnotetext{
${ }^{1}$ É importante esclarecer que se fez a opção de selecionar os estudos de M. Tomasello para orientar o artigo. No entanto, o diálogo com o filósofo da linguagem M. Bakhtin possibilitou estender a reflexão da interação social como movimento que não se encerra nos corpos dos interagentes e abrange também as suas falas em um sentido amplo, pois, qualquer oração é um elo numa cadeia de orações organizada de um modo muito complexo (BAKHTIN, 1981). Como será discutido na seção de resultados, por meio de processos interacionais específicos como, por exemplo, o da imitação do parceiro, as intenções comunicativas são reconhecidas pelas crianças no enredo da brincadeira, e vêm acompanhadas da produção de enunciados condizentes com o contexto interativo.
} 


\section{REVISTA DA ABRALIN}

culturais do meio em que está inserido. O bebê, por exemplo, interpreta o mundo a partir das interações com o outro. O meio cultural compõe-se de uma série de símbolos que necessitam de um ambiente interativo para que haja o compartilhamento de seus significados. A criança não compreende esse sistema simbólico apenas por meio de noções linguísticas (BRUNER, 1997[1990]). O processo de significação ocorre bem antes de a criança utilizar a linguagem verbal. O envolvimento das crianças nas interações sociais com o adulto entendendo-os como agentes intencionais e participando com eles de cenas de atenção conjunta, estabelece as bases para o processo pelo qual a criança aprende a falar, ou seja, para atos de comunicação simbólica, inclusive a linguística (BRUNER, 1983). A linguagem precisa da interação social para constituir-se como uma forma de representação das ações do sujeito mediante trocas recíprocas de conhecimentos nas relações sociais o que dialoga com Bakhtin (1992, p. 92), ao dizer que "para o locutor o que importa é aquilo que permite que a forma linguística figure num dado contexto, aquilo que a torna signo adequado às condições de uma situação concreta dada" e não o reconhecimento de uma forma linguística.

Sabe-se que a capacidade de as crianças representarem, inicia-se mediante suas ações imitativas (CORDEIRO, 1998; NADEL; BAUDONNIÈRE, 1981). Por estarem em um meio social desde o seu nascimento, elas passam por diferentes fases de imitação do comportamento do outro, começando pelos gestos que se transformam em processos de representação e possibilitam a aquisição da linguagem verbal. Nesse processo de adaptação, os movimentos psicomotores oferecem às crianças oportunidades de exploração do ambiente para produzirem representações internalizando-as por meio de suas ações, dado que o desenvolvimento cognitivo é progressivo e está relacionado às ações humanas (VYGOTSKY, 1984).

Levando em consideração as ações imitativas, com intuito de acrescentar novos vocabulários às crianças, no sentido dos gestos, elas oferecerem um caminho para as palavras, assim, as crianças teriam uma habilidade comunicativa mesmo antes de instituir conversações com o outro, mostrando a intersubjetividade como um precursor elementar para a aquisição da linguagem (TREVARTHEN, 2006[1998]). As crianças aprendem novas palavras mediante seus gestos, entendendo os outros como agentes que tem intenções comunicativas e que quer que ela preste atenção a algo específico nas cenas de atenção conjunta. Além disso, a criança precisa inverter o papel com o parceiro no processo de aprendizagem cultural (imitação com inversão de papéis), e assim usar, em relação ao parceiro, o que eles usaram em relação a ela - criar uma convenção comunicativa intersubjetivamente compreendida (um símbolo) (TOMASELLO, 2003; VIANA, 2008).

Ao observar episódios interativos de crianças em situação de brincadeira com pares (cf., por ex. AMORIM, 2012; BORTOLINI; SANTOS, 2020; CARVALHO; PEDROSA, 2003; CORDEIRO, 1998; DIEDRICH, 2020; VIANA, 2008; VIANA; PEDROSA, 2014), fica evidente que as experiências adquiridas no espaço de tempo do brincar contribuem significativamente no processo de comunicação e desenvolvimento da linguagem delas. O comportamento que as crianças apresentam durante a brincadeira demonstra que elas estabelecem suas relações comunicativas por meio do compartilhamento de ideias temáticas e dos diálogos produzidos com o parceiro, fazendo referências a objetos, 


\section{REVISTA DA ABRALIN}

interpretando as ações do outro e trocando informações e experiências conjuntas, uma vez que tais experiências são relevantes para o conhecimento de novas palavras.

Brincar é um comportamento intrinsecamente motivado e relevante para o desenvolvimento humano (NATHAN; PELLEGRINI, 2011). A brincadeira possibilita a criança instituir relações de cooperação, imitação, demonstrar interesse pela atividade do outro, encorajando-as a explorar o meio e a manifestar suas ideias, além de ser um espaço oportuno para ela fazer o uso dos recursos de que dispõem para se comunicar com o outro e falar. Na brincadeira, as crianças compartilham com os parceiros o significado da expressão linguística que ela está usando e abrevia o seu significado. Assim, busca-se, neste artigo, investigar como as crianças de três anos engajam-se em processos de comunicação e de aquisição de linguagem nas interações lúdicas com pares de idade, especificamente quando elas fazem uso de construções abstratas.

\section{Método}

O estudo é de cunho qualitativo. Utilizou-se de registro em vídeo para a observação das interações das crianças em situações de brincadeiras e os dados foram analisados por meio da análise microgenética dos registros videogravados, conforme procedimento proposto por Pedrosa e Carvalho (2005).

\subsection{Participantes}

Participaram da pesquisa 10 crianças, sendo cinco meninos e cinco meninas, estudantes de um Centro Municipal de Educação Infantil (CMEI), com a faixa etária de três anos de idade. A pesquisa se insere no conjunto de investigações que recebeu autorização legal do Comitê de Ética em Pesquisa Envolvendo Seres Humanos (CAEE $n^{\circ}$ 35013814.6.0000.5208; Parecer no 861.609 - 11/11/2014). Também recebeu a anuência da Secretaria de Educação da Prefeitura da Cidade do Recife. Todos os pais das crianças que participaram da pesquisa assinaram o Termo de Consentimento Livre e Esclarecido (TCLE) e autorizaram a participação de seus filhos e divulgação de imagens para fins de formação de docentes e/ou divulgação científica. As crianças foram consultadas e respeitadas quanto a sua vontade em participar da pesquisa. Para divulgação dos resultados os nomes das crianças foram trocados por nomes fictícios.

\subsection{Procedimento de coleta}

Trios de crianças eram convidados para brincar em uma sala previamente organizada com brinquedos industrializados e artesanais expostos sobre uma mesa cercada de cadeiras com 


\section{REVISTA DA ABRALIN}

tamanhos apropriados à altura delas (Figura 1). As crianças recebiam instrução para brincar com o que e como quisessem e as sessões de filmagem duravam 20 minutos.

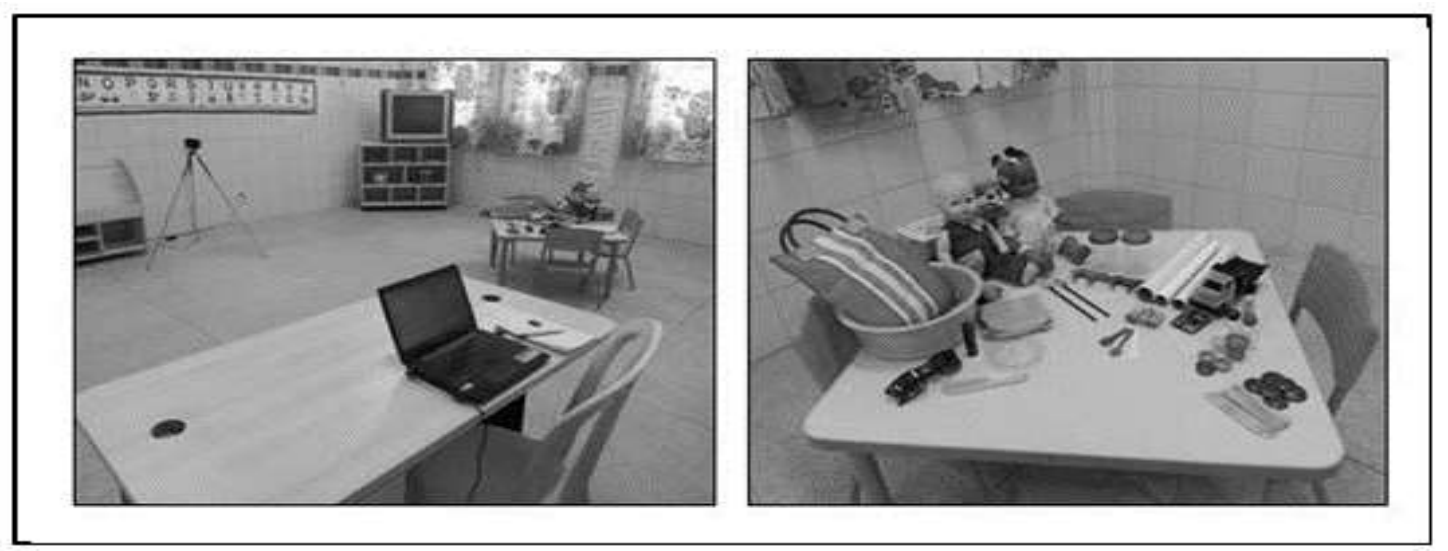

FIGURA 1 - Configuração da sala de coleta de dados e organização da mesa Fonte: elaborada pelos autores.

Nas sessões, foram utilizadas: câmera de filmagem, tripé, mídias de DVD, computador, equipamentos para edição de imagem, brinquedos e sucatas, como bonecas, frasquinhos plásticos, pente, batom, óculos, carrinho, palitos de madeira, copos, fichas plásticas, uma bolsa e uma caixa de papelão.

\subsection{Procedimentos de análise}

Inicialmente, foi realizada a apreciação das videogravações buscando recortar episódios interacionais que fossem reveladores do uso de recursos comunicativos e linguísticos das crianças brincando em situação de brincadeira livre com os seus coetâneos. Episódio é um segmento de vídeo que apresenta de forma clara os indícios do fenômeno que se quer estudar (PEDROSA; CARVALHO, 2005). Como o objetivo deste artigo é investigar como as crianças de três anos de idade, nas suas interações com pares, participam de processos de comunicação e de aquisição de linguagem, os episódios selecionados foram aqueles que exibiam uma sequência interativa que revelavam as intenções comunicativas das crianças na brincadeira e o uso de construções abstratas.

Neste ponto, o foco da análise é dado aos comportamentos reguladores da criança em relação ao seu(s) parceiro(s), os quais evidenciam comportamentos não verbais e verbais na interação entre eles. A criança regula o seu comportamento em função do que ela recorta da ação das outras crianças (PEDROSA; CARVALHO, 2005). Esse momento de regulação provocava o compartilhamento das brincadeiras entre as crianças, e, a partir disso, delimitava-se o início do episódio interativo. Transcrevia-se o seu desenrolar, com o fim estabelecido quando a sequência interativa era interrompida, seja pelo início de um novo episódio, ou porque a sessão se encerrava.

Todas as transcrições de episódios seguiram um roteiro de descrição básico que continha as seguintes informações: título do episódio; data da coleta; duração da sessão; duração do episódio; 


\section{REVISTA DA ABRALIN}

crianças envolvidas (gênero, idade e nomes fictícios); situação - resumo geral do ambiente físico onde se desenrola o episódio; resumo - síntese do próprio episódio; descrição - descrição detalhada de cada um dos momentos em que o episódio foi recortado, indicando-se os minutos e segundos em que eles se iniciam.

As transcrições dos episódios foram conduzidas de forma a ressaltar os aspectos que eram relevantes para a compreensão da comunicação e da aquisição da linguagem da criança mediante a brincadeira livre. O olhar, o sorriso, a imitação dos movimentos e da fala e os gestos que possibilitaram o compartilhamento de intenções comunicativas e o desenvolvimento das habilidades linguísticas constituíram os principais elementos para transcrição e interpretação dos episódios selecionados. Vale ressaltar que a própria transcrição dos episódios se confunde com a análise de dados, dada a seletividade do que se é transcrito (PEDROSA; CARVALHO, 2005).

Também foi desprendida especial atenção no registro das falas das crianças para representar a entonação que elas emitiam no emprego de uma palavra ou frase, colocando a pontuação adequada no trecho e preservando a grafia da palavra ou frase como estas eram emitidas. Todas as sessões foram assistidas repetidas vezes, tanto com o foco em uma criança individualmente, como também olhando o comportamento de cada criança em relação aos parceiros de interação para maximizar a compreensão das pistas comunicacionais reveladas do processo interativo.

As análises das videogravações partiram dos questionamentos inicialmente colocados para este artigo: (a) como crianças de três anos comunicam-se com seus pares de idades na brincadeira? (b) como as crianças de três anos se envolvem no processo de aquisição de linguagem nas brincadeiras com o parceiro? Esses questionamentos guiaram a transcrição e a análise dos episódios interacionais.

De um conjunto de 12 episódios analisados para esta pesquisa, dois foram selecionados para ilustrar a problematização dos objetivos deste estudo, quais sejam: (a) observar as estratégias de comunicação das crianças; (b) investigar como as estratégias de comunicação impulsionam a criança a fazer o uso da linguagem verbal, o que implica em considerar as ações imitativas, os gestos e os movimentos corporais; (c) analisar como as situações de interação social na brincadeira estimulam o desenvolvimento da linguagem, realçando a significância das interações criança-criança, no desenvolvimento das habilidades comunicativas e linguísticas, especificamente o uso de construções abstratas.

\section{Resultados e Discussões}

Ao analisar as transcrições das videogravações de crianças de três anos em situações de brincadeiras, foi possível observar como elas, em suas interações com pares, desenvolveram estratégias de comunicação que as levaram a manifestar suas habilidades linguísticas durante o brincar. No decorrer desta seção de resultados e discussão, explicita-se o quanto o comportamento de uma criança influencia no comportamento de outra, desde suas manifestações não verbais até as verbais. Essas interações revelam as competências comunicativas e linguísticas das crianças pequenas. 


\section{REVISTA DA ABRALIN}

Um primeiro aspecto a ser destacado é que o ambiente em que a criança está inserida influencia no processo de aquisição de linguagem. Bruner (1983) afirma que a aquisição da comunicação prélinguística e linguística acontece, na maioria das vezes, em ambientes reservados como, por exemplo, nas relações dos adultos com as crianças em casa. Argumenta-se, neste artigo, que este processo de aquisição também ocorre em ambientes reservados como nas interações criança-criança e em ambientes preparados para elas. Dessa forma, foi possível perceber que, quando a criança está inserida em um ambiente estruturado com objetos que despertam a sua atenção e com um parceiro de brincadeira, ela começa a falar, a combinar elementos da fala do parceiro à sua própria fala e a fazer referências significativas ao encadeamento do enredo (intersubjetivamente) compartilhado, revelando, assim, suas habilidades linguísticas. As interações criança-criança na brincadeira também têm o seu lugar de destaque como propulsoras para o desenvolvimento da comunicação e da linguagem na infância.

Os resultados encontrados no presente artigo apresentam as estratégias comunicativas das crianças para participarem das brincadeiras, como elas fazem o uso da linguagem não verbal e verbal para se comunicar com o parceiro, suas estratégias de comunicação através da fala, dos olhares, dos sorrisos, dos movimentos corporais, deduzem relações de aproximação do outro e suas ações imitativas na brincadeira. Os dois episódios analisados de crianças em fase de desenvolvimento da linguagem demonstram como a aquisição da linguagem pode acontecer mediante a interação criançacriança e a contribuição da brincadeira para esse processo de aquisição. Apresenta-se o primeiro segmento de episódio.

Episódio 1 - Negociações no faz de conta (Crianças envolvidas: Ellen e Laila)

Ao entrarem na sala, Ellen e Laila brincam em torno de uma mesa preparada com brinquedos. Laila pega a boneca branca e fala olhando para Ellen, com um sorriso no rosto: "Eu quero essa!". No mesmo instante, Ellen olha para a colega, pega a outra boneca e fala sorrindo para Laila e para a pesquisadora: "Eu quero essa, viu tia?". As meninas observam os objetos e os manipulam. Ellen pega um pente e começa a pentear o cabelo da boneca. Ela olha para Laila, que estava observando o que ela estava fazendo, $e$ pergunta: "Tu pegou qual?" referindo-se aos objetos que estavam sobre a mesa. Laila olha para Ellen, levanta um pouco da cadeira, estica o braço e pega um batom que está perto da colega: "Eu pequei o batom.". Ellen fica observando Laila escolher os objetos e fala algo que não se entende com a colega. Enquanto isso Laila escolhe um frasquinho plástico da mesa e diz: "Peguei esse pra minha nenê.". Ellen, que estava observando a colega, olha para a boneca que está segurando e diz: "Vou botar minha nenê pá deitar pá pentear o cabelinho.". Laila olha rápido para Ellen e continua a manusear alguns objetos. Ellen diz: "Eu vou pegar o gagau dela. Pa ela comer." e Laila pergunta: "Cadê? Cadê o gagau dela?" Ellen se debruça sobre a mesa e diz: "Aqui!" pegando um frasquinho. Laila a observa e pega o outro frasquinho igual que estava ao lado do que Ellen pegou, dizendo: "Esse aqui é o gagau dela.". 


\section{REVISTA DA ABRALIN}

Neste segmento, busca-se responder ao questionamento: como as crianças de três anos se comunicam na brincadeira? Pode-se perceber que as meninas exploraram os objetos disponíveis e os selecionam para brincar fazendo o uso de gestos comunicativos e da linguagem. Nota-se que o interesse por um determinado brinquedo, na brincadeira, estimula as crianças a utilizarem suas habilidades linguísticas, como a fala, que através da palavra, torna-se "ponte lançada entre mim e os outros" (BAKHTIN, 1992, p. 113), ou seja, a palavra torna-se um meio de interação para comunicar ao parceiro as suas intenções.

Para Bruner (1983), a aquisição da língua materna é mais rápida, se inserida num contexto lúdico. O pesquisador argumenta que quando a criança brinca com parceiros, ela tem a oportunidade de comunicar os seus desejos e de expressar as suas ideias aos outros. Logo, no início da brincadeira, no momento em que as meninas entram na sala, é possível observar uma troca comunicativa. Laila escolhe a sua boneca fazendo o uso de um sorriso e da linguagem verbal "Eu quero essa!" que comunica a Ellen o seu interesse por brincar junto com a colega. As meninas começam a brincar, demonstrando cuidados com a boneca, segurando-a, colocando-a para dormir e penteando o cabelo (Figura 2).

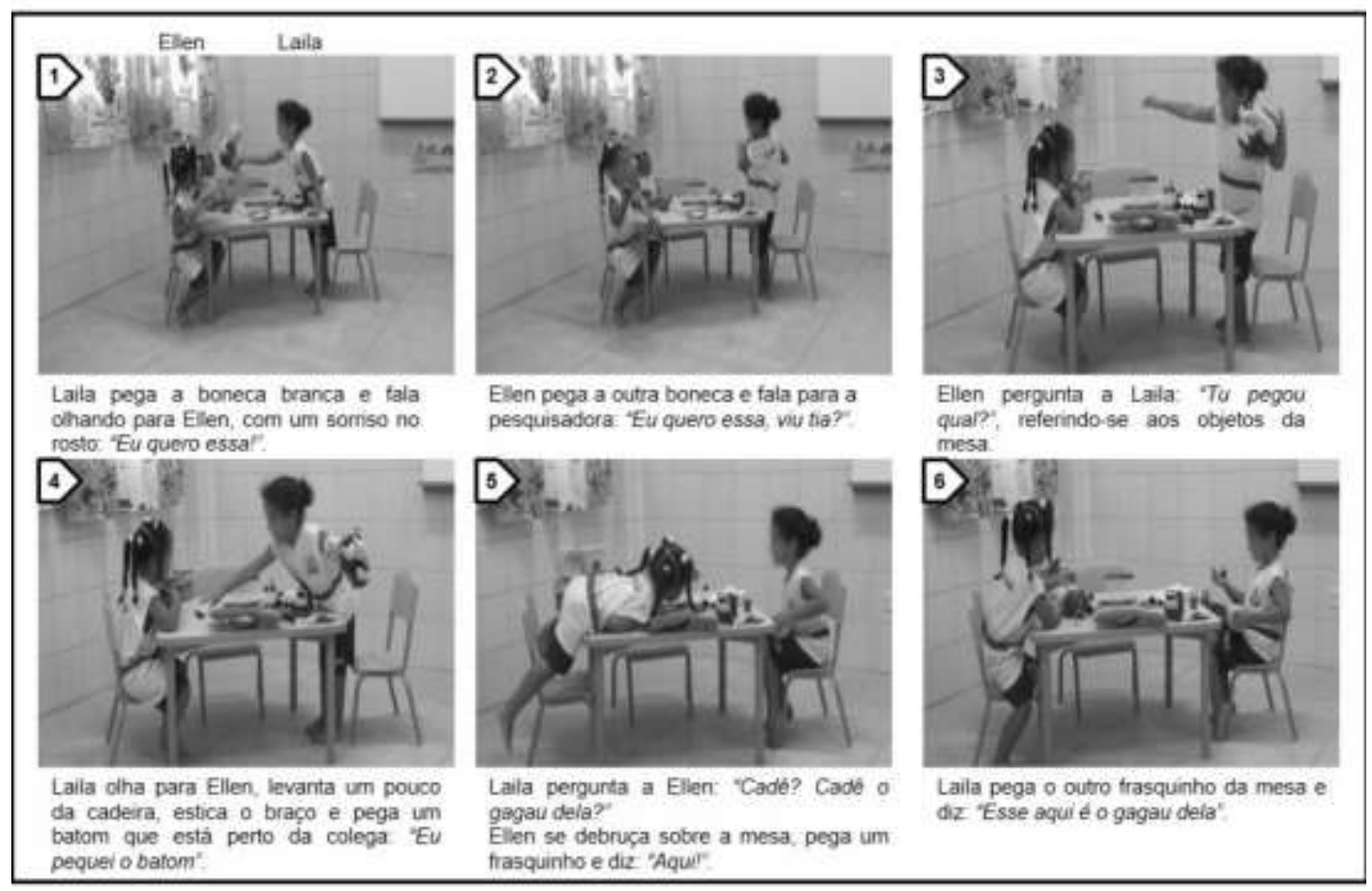

FIGURA 2 - Episódio 1: Negociações no faz de conta

Fonte: elaborada pelos autores.

Outro ponto importante que deve ser chamado à atenção é a disposição das meninas para brincarem juntas, inferida por meio da observação de várias ações imitativas. Quando Laila pega a boneca para si, Ellen observa a colega e faz a mesma coisa, demonstrando interesse pelas ações da colega e disposição para brincar junto. Repetir as ações do outro na imitação é uma forma de demonstrar 


\section{REVISTA DA ABRALIN}

interesse pela mesma atividade. Tais comportamentos possibilitam a instauração de ações coordenadas cooperativas que envolvem as crianças em uma só temática na brincadeira a partir do compartilhamento de intenções (ECKERMAN; PETERMAN, 2001; VIANA; PEDROSA, 2014).

Entende-se também que a ação não verbal impulsiona a criança a fazer o uso da linguagem verbal. Pode-se dizer que as ações não verbais de Laila para brincar com a boneca a estimulou a usar sua habilidade linguística, por meio da fala, para compartilhar com a colega o enredo da brincadeira de faz de conta que desenvolvia com a boneca. Os olhares atentos sobre as ações do outro, os gestos e as expressões faciais são sinais de uma comunicação, que mostram que as meninas estavam compreendendo o que experienciavam juntas. Essas ações estavam acompanhadas de afirmações ("Eu quero essa!"; "Eu peguei o batom.", "Peguei esse pra minha nenê."; "Vou botar minha nenê pá deitar pá pentear o cabelinho."; "Eu vou pegar o gagau dela. Pa ela comer."; "Esse aqui é o gagau dela.") e questionamentos (“Tu pegou qual?"; “Cadê? Cadê o gagau dela?") que abreviavam, com o uso da expressão linguística, o significado da ação, ampliando as chances da mensagem ser compreendida pelo interlocutor. Na brincadeira, as crianças afirmaram os seus enunciados, compartilhando com os parceiros o significado da expressão linguística que elas estavam usando, e, assim, abreviaram este significado. Eventualmente, elas também interrogaram o parceiro, tendo a chance de se certificar sobre a direção que a sua mensagem estava tomando - se estava sendo compreensível ou não para o parceiro no contexto da brincadeira.

No próximo segmento, o foco da discussão recairá sobre as habilidades linguísticas em construções abstratas do tipo afirmativas e interrogativas, e as estratégias de comunicação das crianças em um momento de inserção em uma situação interacional.

Episódio 2 - Recebendo um parceiro na brincadeira (Crianças envolvidas: Ellen, Laila e Paula)

Laila e Ellen estão brincando de faz de conta de mãe e filha. Paula entra na sala e as meninas começam a sorrir e dar pulinhos de alegria. Laila olha para Paula mostrando a boneca que estava segurando $e$ dizendo: "Eu peguei uma nenê!" depois ela pergunta: "Tu quer um batom?" Paula vai em direção a Laila que estava sentada com a boneca. Ellen se aproxima de Paula e fala: "Deixa eu botar batom em tu, Paula? Deixa eu botar batom em tu?" Paula balança a cabeça sinalizando que não quer. Laila se aproxima das meninas e diz: "Olha, eu já passei batom! Eu já passei.". Paula e Ellen olham para Laila. Em seguida, Ellen passa batom em Laila e diz: "Ela deixa. Paula não deixa.". Logo em seguida Ellen passa batom em si mesma. Paula observa as meninas e depois vai em direção a mesa, pega dois frasquinhos de plástico, se aproxima de Ellen sorrindo e diz: "Olha o que que achei!" Esticando o braço com os frasquinhos na direção de Ellen. Ellen olha para a colega, estica o braço para pegar um dos frasquinhos da mão de Paula e diz: "É meu perfume!" Ellen simula passar perfume em Paula, fingindo borrifar líquido na colega e fazendo um som "tchi, tchi, tchi". Paula com o outro frasquinho repete o que Ellen disse, "É meu perfume!". A garota simula passar perfume em si mesma, fingindo derramar perfume pelo corpo e fazendo um som "tchi, tchi, tchi". 


\section{REVISTA DA ABRALIN}

Quando Paula se aproxima das colegas, elas começam a exibir os brinquedos que estavam segurando e a oferecer os objetos que estavam sobre a mesa. A oferta de brinquedos também pode ser interpretada como uma forma de levar Paula a imitar as ações da dupla na brincadeira. As meninas, no curso da interação, imitam uma a outra e estabelecem um contato social. As expressões de alegria, junto como os pulinhos e os sorrisos de Ellen e Laila, comunicam a Paula que ela era bem-vinda na brincadeira.

No momento da oferta de brinquedos, Laila, Ellen e Paula apresentam suas habilidades linguísticas e estabelecem uma conversa com as seguintes construções abstratas: afirmativas ("Eu peguei uma nenê!"; "Olha, eu já passei batom! Eu já passei."; "Ela deixa. Paula não deixa."; "Olha o que que achei!"; "É meu perfume!") e interrogativas (“Tu quer um batom?"; "Deixa eu botar batom em tu, Paula? Deixa eu botar batom em tu?").

É importante salientar que, antes de Paula entrar na sala, Laila e Ellen estavam brincando de passar batom uma na outra e, assim, quando Paula entra na sala, Ellen e Laila perguntam se ela quer passar batom também, o que seria uma maneira de incluir Paula na brincadeira. Paula não responde verbalmente às meninas, ela balança a cabeça comunicando de forma não verbal que não estava interessada em passar batom. Interpreta-se que, como Paula não aceita passar batom, Ellen vira-se para Laila e passa batom na garota diante de Paula, dizendo: "Ela deixa. Paula não deixa.". Pode-se dizer que esse comportamento de Ellen (movimento do corpo junto com a fala) foi uma estratégia usada para comunicar a Paula que, "passar batom" poderia ser uma brincadeira interessante. Refletese também que Ellen deixa claro na sua fala ("Ela deixa. Paula não deixa.") que ela sabe qual a parceira que está topando a brincadeira no momento.

Apesar de Paula não demonstrar interesse em brincar de passar batom, ela chama a atenção das meninas para outros objetos da sala. Paula estica o braço mostrando os frasquinhos plásticos e diz: "Olha o que que achei!". Imediatamente, Ellen olha para a Paula e pega um dos frasquinhos. Nesse mesmo momento, a sequência interativa se desenrola por meio de ações imitativas dos gestos e da fala do outro: tanto Paula quanto Ellen fingem passar perfume com os frasquinhos, dizem "É meu perfume!" e fazem um som "tchi, tchi, tchi" - criando uma "palavra" nova para a brincadeira.

Observa-se que, no instante em que as crianças escolhem os brinquedos, seus gestos comunicam de forma não verbal ao parceiro o seu interesse de brincar com aquele objeto. Esse tipo de comunicação é considerado como trocas intersubjetivas (TREVARTHEN, 2006[1998]). Essas trocas representam um sinal para o outro sobre as intenções comunicativas implícitas na interação (AMORIM, 2012). Ao exibir esse sinal, o parceiro de interação tem chances de capturar o que o outro quer comunicar.

As ações imitativas que as crianças apresentaram ao longo das brincadeiras em relação às ações do parceiro podem ser consideradas como uma tentativa de comunicar o seu interesse em fazer parte da brincadeira do colega. A ludicidade estimula a comunicação das crianças de diferentes maneiras, seja através das palavras, dos gestos ou da imitação. A forma como as crianças manifestavam suas habilidades linguísticas, no momento em que brincam, diz respeito à necessidade de se 


\section{REVISTA DA ABRALIN}

comunicar com o outro. Dessa forma, no decorrer das observações deste episódio pergunta-se: como crianças de três anos envolvem-se em processos de aquisição de linguagem na brincadeira?

O desenvolvimento da linguagem não se limita apenas à fala, mas também às ações do sujeito sobre o meio em que está inserido (CORDEIRO,1998). O desejo de descobrir o que é um determinado objeto, de mostrar ao outro o que achou ou o que está fazendo, impulsiona a criança a fazer o uso da linguagem verbal. Por isso, a presença de um parceiro na brincadeira, influencia o desenvolvimento da linguagem. Na brincadeira, as crianças desenvolvem suas habilidades comunicativas a partir das interações com o outro (PEDROSA; CARVALHO, 2006). A aproximação com o parceiro e a necessidade de conquistar algo na brincadeira, leva a criança a enunciar, pois como diz Bakhtin (1992, p. 121), "a enunciação enquanto tal é um puro produto da interação social".

É interessante notar que a brincadeira oferece à criança oportunidades de estabelecer relações significativas com o outro e essas oportunidades contribuem para a aquisição de linguagem visto que, de certa forma, incentivam a criança a desenvolver a fala.

$\mathrm{O}$ ato de acompanhar o parceiro na brincadeira e repetir o que ele faz e fala são ações significativas para o desenvolvimento da linguagem, já que as relações interativas que as crianças estabelecem entre si, quando estão brincando, favorecem as manifestações de saberes, o compartilhamento de experiências e trocas de linguagens. A brincadeira oferece a criança oportunidades para pensar, falar, criar novas palavras, inventar histórias de faz de conta ou até mesmo reproduzir situações da sua realidade cotidiana.

As crianças apresentaram ações imitativas na brincadeira e as usaram como um poderoso meio de comunicação. Além disso, as práticas imitativas não verbais apresentadas pelas crianças quando elas estão brincando, permitem que elas entendam o que estão realizando juntas. Esta compreensão fortalece o enredo da brincadeira e vem acompanhada da produção de enunciados condizentes com o contexto interativo. Aos poucos essa compreensão se complexifica na medida em que a criança reconhece e referencia palavras mencionadas pelo parceiro introduzindo-as ao roteiro de brincadeira e seleciona a situação adequada para o seu emprego. Tudo isso dentro de um contexto em que as intenções comunicativas são reconhecidas.

\section{Conclusão}

Por intermédio de uma análise microgenética, o presente artigo permite expandir estudos sobre a comunicação e a aquisição de linguagem nas interações criança-criança em crianças falantes de português brasileiro. Presume-se que os episódios aqui apresentados, os quais refletem processos interacionais de crianças em situações de brincadeira, possam oferecer referências empíricas que contribuam para discussões e para o fortalecimento de pesquisas sobre o desenvolvimento da comunicação e da linguagem como processos que se efetivam no uso mediante as necessidades interacionais.

Durante as suas interações, as crianças estão atentas às ações dos parceiros, e tais ações as estimulam a manifestar suas habilidades e compreender o que estão realizando simultaneamente. 


\section{REVISTA DA ABRALIN}

Esses processos interativos favorecem a aquisição da língua, aqui exemplificadas por meio de construções abstratas afirmativas e interrogativas. Nota-se que as estratégias de comunicação verbal e não verbal das crianças são fortemente marcadas por ações imitativas. Observa-se também o papel fundamental dos movimentos do corpo nesse processo.

Com base na discussão apresentada, reforça-se que as crianças de três anos de idade constroem competências comunicativas e linguísticas ao longo das atividades compartilhadas entre os parceiros na brincadeira. Dessa forma, partindo da concepção de que os processos de comunicação e de aquisição de linguagem se desenvolvem nas interações com o outro e em ambientes adaptados para esta finalidade, observamos que o ambiente da brincadeira com pares é importante na infância.

Algumas limitações são consideradas. Os temas abordados neste artigo têm grande abrangência. Essa característica implicou escolhas como, por exemplo, priorizar a análise de um processo de comunicação e de aquisição da língua no qual a criança identifica intenções comunicativas por meio de gestos, dispondo-se desse fator como pista para a interpretação de atos intencionais que reconhece e referencia palavras mencionadas pelo outro, em detrimento de um aprofundamento nos aspectos formais da aquisição da linguagem em termos analíticos, morfológicos e lexicais. Futuros estudos podem aproveitar as características da comunicação criança-criança de três anos na interação qualificada neste artigo, e detalhar os aspectos formais da aquisição de crianças em interação em diferentes idades.

Outro aspecto importante a ser realçado é que o método adotado, se por um lado tem ganhos por possibilitar recortar unidades de análise episódicas para refletir sobre o processo de comunicação e aquisição de linguagem na interação criança-criança, por outro lado, pode ser aprimorado associando, ao recorte de unidades episódicas interacionais, o uso de ferramentas específicas para anotação de gravações de áudio e vídeo e de análise de transcrição, como por exemplo o Eudico Language Annotator (ELAN) - software desenvolvido pelo Max Planck Institute for Psycholinguistics, em Nijmegen, na Holanda (ELAN, 2020). Como no ELAN as anotações são alinhadas no tempo, o uso dessa ferramenta, em futuros estudos criança-criança, pode potencializar o rastreamento das falas das crianças com o foco, tanto no encadeamento das aquisições linguísticas, quanto em uma análise descritiva e sequencial das falas. Isso pode maximizar a qualidade do dado e as suas possibilidades de análise.

Por fim, salienta-se que o processo de comunicação e de aquisição da linguagem advém de um conjunto de fatores sociais, cognitivos e interativos, em razão de que, as crianças necessitam e se beneficiam da convivência com o outro para desenvolver suas habilidades linguísticas mediante suas capacidades comunicativas. A partir do momento que a criança começar a falar, a linguagem lhe oferece uma série de possibilidades para a construção de enunciados, permitindo-lhe agir criativamente conforme as suas necessidades.

Assim, espera-se que as reflexões aqui realizadas contribuam para a integração da brincadeira criança-criança nos estudos da comunicação e da linguagem, que as crianças tenham mais oportunidades de interação social lúdica com os seus pares nos espaços em que convivem cotidianamente e que os adultos aprendam a saber ouvir e reparar o que elas têm a dizer. 


\section{REVISTA DA ABRALIN}

\section{REFERÊNCIAS}

AMORIM, K. Processos de Significação no Primeiro Ano de Vida. Psicologia: Teoria e Pesquisa, v. 28, n. 1, p. 45-53, 2012.

BAKHTIN, M. Marxismo e filosofia da linguagem. 6. ed. São Paulo: Editora Huritec, 1992.

BAKHTIN, M. The dialogic imagination. Austin: University of Texas Press, 1981.

BOHN, M.; KACHEL, G.; TOMASELLO, M. Young children spontaneously recreate core properties of language in a new modality. Proceedings of the National Academy of Sciences, v. 116, n. 51, p. 26072-26077, 2019. DOI: https://doi.org/10.1073/pnas.1904871116

BORTOLINI, F. L.; SANTOS, J. R. F. DOS. A experiência da criança nas relações entre aquisição da linguagem, fala e escrita. Revista da ABRALIN, v. 19, n. 2, p. 1-5, 14 ago. 2020. DOI: http://doi.org//10.25189/rabralin.v19i2.1614

BRUNER, J. Atos de significação. Porto Alegre: Artes Médicas, 1997. 130 p. (Original escrito em 1990).

BRUNER, J. Child's talk: learning to use language. New York/London: W. W. Norton \& Company, 1983. 144 p.

CAMERON-FAUlKNER, T.; MALIK, N.; STEELE, C.; CORETTA, S.; SERRATRICE, L.; LIEVEN, E. A Cross-Cultural Analysis of Early Prelinguistic Gesture Development and Its Relationship to Language Development. Child Development, v. 92, n.1, p. 1-8, 2020. DOI: https://doi.org/10.1111/cdev.13406

CARVALHO, A. M. A.; PEDROSA, M. I. Precursores filogenéticos e ontogenéticos da linguagem: reflexões preliminares. Revista de Ciências Humanas, v. 34, n. 1, p. 219-252, 2003.

CORDEIRO, G. S. Da ação à linguagem na interação criança-criança: um processo de construção. Tese (Doutorado em Linguística Aplicada e Estudos da Linguagem) - Universidade Católica de São Paulo (PUC), São Paulo, 1998.

DIEDRICH, M. S. A criança e a vivência das regras de interação na conversação. Domínios de Lingu@gem, v. 14, n. 1, p. 218-234, 11 fev. 2020. DOI: https://doi.org/10.14393/DL40-v14n1a2020-8

ECKERMAN, C. O.; PETERMAN, K. Peers and infant social/communicative development. In: BREMNER, G.; FOGEL, A. (Eds.). Blackwell handbook of infant development. Oxford, UK: Blackwell, 2001. p. 226-350. DOI: https://doi.org/10.1002/9780470996348.ch12

ELAN. Software de computador. Versão 6.0. Nijmegen: Max Planck Institute for Psycholinguistics, The Language Archive, 2020. Obtido em: https://archive.mpi.nl/tla/elan

LIEVEN, E.; BEHRENS, H.; SPEARES, J.; TOMASELLO, M. Early syntactic creativity: a usage-based approach. Journal of Child Language, v. 30, n. 2, p. 333-370, 2003. DOI: https://doi.org/10.1017/S0305000903005592

LISZKOWSKI, U.; BROWN, P.; CALLAGHAN, T.; TAKADA, A.; DE VOS, C. A prelinguistic gestural universal of human communication. Cognitive Science, v. 36, n. 4, p. 698-713, 2012. DOI: https://doi.org/10.1111/j.15516709.2011.01228.x

NADEL, J.; BAUDONNIÈRE, P. M. Imitação, modo preponderante de intercâmbio entre pares, durante o terceiro ano de vida. São Paulo: Caderno de Pesquisa, n. 39, p. 26-31, 1981.

NATHAN, P.; PELLEGRINI, A. D. (Eds.). The Oxford Handbook of the Development of Play. Oxford: Oxford University Press, 2011. DOI: https://doi.org/10.1093/oxfordhb/9780195393002.001.0001 


\section{REVISTA DA ABRALIN}

PEDROSA, M. I.; CARVALHO, A. M. A. Análise qualitativa de episódios de interação: uma reflexão sobre procedimentos e formas de uso. Psicologia: Reflexão e Crítica. v. 18, n. 3, p. 431-442, 2005. DOI: https://doi.org/10.1590/S0102-79722005000300018

PEDROSA, M. I.; CARVALHO, A. M. A. Construction of communication during young children's play. Revista de Etologia, v. 8, n. 1, p.1-11, 2006.

RISSMAN, L.; GOLDIN-MEADOW, S. The Development of Causal Structure without a Language Model. Language Learning and Development, v. 13, n. 3, p. 286-299, 2017. DOI: https://doi.org/10.1080/15475441.2016.1254633

TOMASELLO, M. Do young children have adult syntactic competence? Cognition, v. 74, n. 3, p. 209-253, 2000. DOI: https://doi.org/10.1016/s0010-0277(99)00069-4

TOMASELLO, M. Origens culturais da aquisição do conhecimento humano. São Paulo: Martins Fontes, 2003.

TOMASELLO, M. Origins of human communication. Cambridge, MA: MIT Press, 2008.

TREVARTHEN, C. The concept and foundations of infant intersubjectivity. In: BRATEN, S. (Ed). Intersubjective communication and emotion in early ontogeny. Cambridge: Cambridge University Press, 2006. (Trabalho original escrito em 1998)

VIANA, K. M. P. Observando crianças e refletindo sobre o papel do movimento na comunicação. 179 f. Dissertação (Mestrado em Psicologia) - Departamento de Psicologia, Universidade Federal de Pernambuco, Recife, 2008.

VIANA, K. M. P.; PEDROSA, M. I. Brincadeiras Coordenadas Cooperativas e o Compartilhamento de Intenções em Crianças. Psicologia: Reflexão e Crítica, v. 27, n. 3, p. 564-572, 2014. DOI: http://dx.doi.org/10.1590/16787153.201427318

VYGOTSKY, L. S. A formação social da mente. São Paulo: Martins Fontes, 1984.

VYGOTSKY, L. S. Pensamento e linguagem. São Paulo: Martins Fontes, 1993. 